\begin{tabular}{lccc} 
& Berechnet : & & Gefunden : \\
$\mathrm{C}^{6}$ & $\mathbf{7 2}$ & 40,22 & 40,18 \\
$\mathrm{H}$ & 4 & 2,23 & 4,46 \\
$\mathrm{Cl}^{2}$ & 71 & - & - \\
$\mathrm{O}^{2}$ & 32 & $\cdots$ & - \\
\cline { 2 - 4 } & 179. & &
\end{tabular}

In dem kurzen Auszuge dieser Arbeit in der Zeitschrift für Chemie 1867, 727 gab ich an, dass Dichlorchinon in alkoholischer Lösung nach Zusatz von Eisenchlorid feine weisse Nadeln abscheide. Bei Wiederholung dieses Versuches hat es mir nicht gelingen wollen, diese Nadeln wieder zu erhalten.

Göttinge n, im Sommer 1868 .

\title{
Notiz über Fleischextract
}

von Dr. Enders, Apotheker in Creuzburg.

Seitdem das anerikanische Fleischextract, welches nach Prof. v. Liebig's Vorschrift von Giebert in Fras Bentos (Urugnay) bereitet wird, die seiner Yortrefflichkeit gebührende günstige Aufnahme und grosse Verbreitung gefunden hat, regt sich an vielen Orten, die sich für eine derartige Fabrikation eignen, die Concurrenz und es bilden sich fortwährend Gesellschaften, in Amerika sowohl, wie in Australien, welche sogenanntes Liebig'sches Fleischextract darstellen. So z. B. fabricirt ein Herr Robert Tooth in Sydney (Australien) ein Fleischextract, welches unter dem Namen: „das ächte Fleischextract (Methode Liebig's)“ durch die Herren Coleman \& Comp. in London in den europäischen Handel gebracht wird. In einer, den Sendungen beigegebenen Schrift, die u. A. verschiedene Vorschriften zur Verwendung des Extracts für Suppen, Saucen etc. enthält, ist gesagt, dass Proben von jeder Sendung dieses Extracts durch den Herrn Dr. W. A. Miller, Prof. der Chemie am Kings College in London analysirt werden. Ilas Extract 
befindet sich in Porzellanbüchsen, die mit Stanniol und Pergamentpapier verschlossen sind. In Hamburg findet sich dieses australische Extract häufig in Apotheken und Materialläden. - Ein anderes Fleischextract, welches ich gleichfalls in Hamburg zu sehen Gelegenheit hatte, stammte aus Amerika; es lag eine Probe in einem Glasgefässe und eine zweite in einer Büchse von Weissblech, nicht sehr sauber verpackt, vor. Auf beiden Gefässen war eine in französischer und spanischer Sprache gedruckte Gebrauchsanweisung angeklebt; der Name des Verfertigers, resp. Verkäufers, war darauf nicht angegeben. Das australische Extract erschien dunkler gefärbt, als das amerikanische und klarer, d. h. es enthielt weniger körnige, krümlige Substanzen als dieses; se in Geschmack war etwas anders; mir erschien er weniger angenebm, als der des amerikanischen Extracts. - Für den Consumenten liegt wohl kaum ein Grund vor, statt des Extractes von Fray Bentos irgend ein anderes zu verwenden, da dasselbe in seinen Eigenschaften keinem anderen nachsteht. Das Giebert'sche Extract wird bekanntlich in Europa durch Prof. v. Liebig und Prof. v. Pet tenk ofer einer sorgfältigen Prüfung unterworfen und es gelangen nur diejenigen Sendungen in den europäischen Handel, wclche sich probehaltig erwiesen haben; es hat also der Apotheker für seinen verhältnissmässig geringen Verbrauch eine Prüfung dieses Extractes nicht nöthig; andere derartige Präparate jedoch wird er einer vergleichenden Prüfung unterwerfen müssen. Obgleich hierbei immer der Geschmack das wesentlichste Kriterium für die Güte des Extractes bleiben wird, so hat man ausserdem stets den Gehalt an Wasser, die Asche und die Menge des in Weinge ist löslichen Theiles zu bestimmen, um das untersuchte Extract mit dem von Fray Bentos vergleichen zu können.

1) Die Wasserbestimmung geschieht am Besten in folgender Weise. Man wägt zwei gut auf einander schliessende Uhrgläser nebst Klemmer, bringt auf das eine höchstens 1 Grin. Extract und trocknet im Luftbade bei $100-110^{\circ} \mathrm{C}$. 
bis zum constanten Gewicht. Das Extract ist sehr hygroscopisch, man muss daher nach jedem Trocknen die Uhrgläser sofort schliessen und unter dem Exsiccator erkalten lassen. Nimmt man die Austrocknung im Platintiegel vor, so kann man zwar dieselbe Extractmenge nachher zur Aschenbestimmung verwenden; da jedoch ein Tiegel nie so genau, wie abgeschliffene Uhrgläser schliesst, so nimmt das Gewicht meist schon wäbrend des Wägens sehr rasch wieder zu; auch trocknet das Extract im Tiegel viel langsamer aus, ich ziehe desshalb die erste Methode vor.

2) Die Aschenbestimmung. Man erhitzt höchstens 1 Grm. Extract langsam im Platintiegel, glüht zuletzt stärker, bis die Asche fast weiss erscheint und wägt rasch nach dem Erkalten. Wegen des starken Aufblähens ist anfangs ein sehr langsames Erhitzen nöthig, damit die Masse nicht übersteige. Die Asche ist sehr hygroscopisch, sie zerfliesst an der Luft.

3) Der weingeistige A uszug. Es ist zu bestim. men, wieviel von dem Extract in 80 proc. Weingeist löslich ist. Hierbei ist es nicht rathsam, das Extract direct mit Weingeist zu übergiessen, da es sich in diesem Falle zusammenballt und man genöthigt ist, es stundenlang und wièderholt mit Weingeist zu verreiben, um es vollständig auszuziehen, auch würde es, da das Extract selbst Wasser enthält, nöthig sein, nach der Entfernung des Weingeistes den Rückstand nochmals mit 80 proc. Weingeist auszuzichen. Besser und rascher kommt man auf folgende Weise zum Ziele. Man tarire ein kleines Becherglas nebst Glasstab und wäge 1-2 Grm. Extract hinein. Sodann bringt man dazu einige CC. destillirtes Wasser, löst das Extract durch Umrühren und giesst die Lösung mit Hilfe eines kleinen Trichters in eine Flasche, welche $100 \mathrm{CC}$. absoluten Alkohol enthält. Das Becherglas wird mit soviel Wasser nachgespült, dass davon im Ganzen 15 CC. in Anwendung kommen, das Nachgespülte selbstverständlich zum Alkohol gegossen; es scheidet sich darin eine Menge Unlösliches, zunächst im fein- 
ster Vertheilung, ans. Nachdem der Inhalt der Flasche gehörig durchgeschüttelt ist, lässt man ihn einige Stunden ruhig stehen, das Ungelöste lat sich dann hinlänglich fest an die Glaswände angesetzt, dass man die Lösung klar abgiessen kann. (Filtriren ist hier nicht nothwendig). Auf den Rückstand giesst man etwas 80 prcc. Weingeist, schüttelt durch, filtrirt, wäscht mit Weingeist aus und entfernt aus den vereinigten Flüssigkeiten den Alkohol durch Destillation, oder besser durch Abdampfen. Wenn der Abdampfrückstand dünne Extractconsistenz erlangt hat, wird er mit etwa $50 \mathrm{CC}$. Weingeist von 80 Procent übergossen. Der grösste Theil wird sich hierbei lösen, die noch ungelöst bleibenden Flocken werden durch Filtriren getrennt, gut ausgewaschen und das Filtrat abgedampft. Da bekanntlich weingeistige Flüssigkeiten die Eigenschaft haben, beim Abdampfen am Rande der Gefässe emporzusteigen, so geschieht das Abdampfen am Zweckmässigsten in einem hohen Becherglase, welches man in ein nur gelinde erwärmtes Wasserbad einsetzt, damit die Flüssigkeit nicht zum Kochen, bezw. Verspritzen kommen kann. Jer zuletzt bleibende Riuckstand wird am Besten auf einer gewogenen Uhrschale im Wasserbade eingedampft, dann im Luftbade bei $100-110^{\circ} \mathrm{C}$. ausgetrocknet; wobei man wieder ganz ebenso zu verfahren hat, wie bei der Bestimmung des Wassers. Dieser in Weingeist lösliche Theil des Extractes ist gleichfalls sehr hygroscopisch.

Dass das Fleischextract keine metallischen Verunreinigungen enthalten darf, braucht wohl nicht noch besonders erwähnt zu werden. Das fräher erwähnte amerikanische Fxtract, welches sich in einer Blechbüchse befand, enthielt, besonders in den Partieen, die der Wandung der Büchse anlagen, eine beträchtliche Menge Zinn, sowie eine nur äusserst geringe Spur Kupfer.

Das amerikanische Extract ergab folgende Mengen:

$\begin{array}{ll}\text { Wasser } & 32,53 \% \\ \text { Asche } & 12,83, \\ \text { In Weingeist lösl. Extract } & 36,02,\end{array}$


Ceb. d. bisher angew. Essigproben u. ein. Essig-Gehaltsprüfungs-Apparat. 219

Das australische Extract von Tooth ergab:

$\begin{array}{ll}\text { Wasser } & 21,34 \% \\ \text { Asche } & 21,66, \\ \text { In Weingeist Lösliches } & 57,72,\end{array}$

Diese letzteren Resultate weichen wesentlich ab von denen des Prof. Miller und Dr. Wimmel, welche fanden: in 100 Theilen Prof Miller. Dr. Wimmel. Wasser $12,17 \mathrm{Th}$. $12,72 \mathrm{Th}$.

Asche 23,02 " 22,51 ” In Weingeist Löslich. 68,83 " 69,05,

Woher eine so grosse Verschiedenheit eines Präparates aus derselben Fabrik entstehen konnte, vermag ich nicht zu erklären; jedenfalls entstammte das von mir untersuchte Extract einer ganz anderen, späteren Sendung.

\section{Ueber die bisher angewendeten Essigproben und einen Esslg-Gehaltsprufungs-Apparat nach Prof. Fleck's Methode}

von W. A. Herb, Apotheker in Pulsnitz (Sachsen).*)

Der Essig ist der Hauptsache nach eine Mischung von Wasser und Essigsäure, deren Mengenverhältniss sich init der Senkwaage aus mehrfachen Gründen nicht bestimmen lässt, daher man zur Gehaltsprüfung auf die Sättigung des Essigs mit einem Alkali oder Metalloxyd angewiesen ist.

Das älteste Verfahren, nach welchem man zu diesem Zwecke arbeitete, bestand darin, dass man 4 I Loth Essig abwog und dann die Menge von chemisch reiner Potasche dem Gewichte nach bestimmte, welche man nöthig hatte, um den abgewogenen Essig zu neutralisiren und essigsaures Kali zu erzeugen. Das Gewicht bestimmte man nach Granen (wovon

*) Besonderer Abdruck aus Dingler's polytechnischem Journal Bd. CLXXXVJ. S. 119, 2weites Octoberbeft 1867. 